\title{
Impact of body mass index on tumor recurrence among patients undergoing curative-intent resection of intrahepatic cholangiocarcinoma- a multi-institutional international analysis
}

\author{
Katiuscha Merath a, Rittal Mehta a, J. Madison Hyer a, Fabio Bagante a, b, Kota Sahara a, o, \\ Sorin Alexandrescu ${ }^{c}$, Hugo P. Marques ${ }^{\mathrm{d}}$, Luca Aldrighetti ${ }^{\mathrm{e}}$, Shishir K. Maithel ${ }^{\mathrm{f}}$, \\ Carlo Pulitano ${ }^{g}$, Matthew J. Weiss ${ }^{\mathrm{h}}$, Todd W. Bauer ${ }^{\mathrm{i}}$, Feng Shen ${ }^{\mathrm{j}}$, George A. Poultsides ${ }^{\mathrm{k}}$, \\ Olivier Soubrane ${ }^{1}$, Guillaume Martel ${ }^{\mathrm{m}}$, B. Groot Koerkamp ${ }^{\mathrm{n}}$, Alfredo Guglielmi ${ }^{\mathrm{b}}$, \\ Endo Itaru ${ }^{\circ}$, Aslam Ejaz ${ }^{a}$, Timothy M. Pawlik ${ }^{\mathrm{a}, ~ *}$
}

a The Ohio State University Wexner Medical Center, Columbus, OH, USA

${ }^{\mathrm{b}}$ University of Verona, Verona, Italy

${ }^{\mathrm{c}}$ Fundeni Clinical Institute, Bucharest, Romania

d Curry Cabral Hospital, Lisbon, Portugal

e Ospedale San Raffaele, Milan, Italy

${ }^{\mathrm{f}}$ Emory University, Atlanta, GA, USA

${ }^{g}$ University of Sydney, Sydney, Australia

h Johns Hopkins Hospital, Baltimore, MD, USA

${ }^{i}$ University of Virginia, Charlottesville, VA, USA

j Eastern Hepatobiliary Surgery Hospital, Shanghai, China

${ }^{\mathrm{k}}$ Stanford University, Stanford, CA, USA

${ }^{1}$ Beaujon Hospital, Clichy, France

$\mathrm{m}$ University of Ottawa, Canada

${ }^{\mathrm{n}}$ Erasmus University Medical Center, Rotterdam, Netherlands

${ }^{\circ}$ Yokohama City University, Yokohama, Japan

\section{A R T I C L E I N F O}

\section{Article history:}

Accepted 1 March 2019

Available online 7 March 2019

Keywords:

Intrahepatic cholangiocarcinoma

Recurrence

BMI

Obesity

Prognosis

\begin{abstract}
A B S T R A C T
Background: The association between body mass index (BMI) and long-term outcomes of patients with ICC has not been well defined. We sought to define the presentation and oncologic outcomes of patients with ICC undergoing curative-intent resection, according to their BMI category.

Methods: Patients who underwent resection of ICC were identified in a multi-institutional database. Patients were categorized as normal weight (BMI $18.5-24.9 \mathrm{~kg} / \mathrm{m}^{2}$ ), overweight (BMI $25.0-29.9 \mathrm{~kg} / \mathrm{m}^{2}$ ) and obese (BMI $\geq 30 \mathrm{~kg} / \mathrm{m}^{2}$ ) according to the World Health Organization (WHO) definition. Impact of clinico-pathological factors on recurrence-free survival (RFS) was assessed using Cox proportional hazards model among patients in the three BMI categories.

Results: Among a total of 790 patients undergoing curative-intent resection of ICC in the analytic cohort, 399 (50.5\%) had normal weight, 274 (34.7\%) were overweight and $117(14.8 \%)$ were obese. Caucasian patients were more likely to be obese $(66.7 \%, \mathrm{n}=78)$ and overweight $(47.1 \%, \mathrm{n}=129)$ compared with Asian (obese: $18.8 \%, n=22$; overweight: $46 \%, n=126$ ) and other races (obese: $14.5 \%, n=17$; overweight: $6.9 \%, \mathrm{n}=19)(\mathrm{p}<0.001)$. There were no differences in the presence of cirrhosis (10.9\%, vs. $12.8 \%$, vs. $12.9 \%)$, preoperative jaundice (8.6\% vs. 9.5\% vs. $12.0 \%$ ), or levels of CA 19-9 (75, IQR 24.6-280 vs. 50.9, IQR 17.9 -232 vs. 43, IQR 16.9-192.7) among the BMI groups (all $\mathrm{p}>0.05$ ). On multivariable analysis, increased BMI was an independent risk factor for tumor recurrence (OR 1.16, 95\% CI $1.02-1.32$, for every 5 unit increase).
\end{abstract}

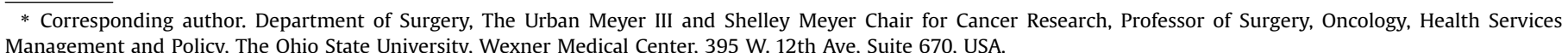

E-mail address: tim.pawlik@osumc.edu (T.M. Pawlik). 
Conclusion: Increasing BMI was associated with incremental increases in the risk of recurrence following curative-intent resection of ICC. Future studies should aim to achieve a better understanding of BMIrelated factors relative to prognosis of patients with ICC.

(c) 2019 Elsevier Ltd, BASO The Association for Cancer Surgery, and the European Society of Surgical Oncology. All rights reserved.

\section{Introduction}

In 2014, the World Health Organization (WHO) reported that more than 1.9 billion (39\%) adults are overweight and more than 600 million (13\% of the world's adult population) are obese [1]. In the United States (U.S.), these numbers are even higher, with approximately $69 \%$ of the adult population being overweight and $35 \%$ being obese. Estimates suggest that by 2030 , obesity among U.S. adults will increase by at least $33 \%$, such that $42-51 \%$ of the adult population will be obese, with the prevalence of severe obesity being $11 \%$ [2]. In light of the increase in obesity worldwide, obesityassociated cancer has become a major health concern and an economic burden [3]. According to the 2016 update of the International Agency for Research on Cancer (IARC), obesity is an established risk factor for several types of cancers, including colorectal; esophageal adenocarcinoma, cancer of the gastric cardia, gallbladder, pancreas, liver, kidney, breast, multiple myeloma, among others [4-7].

Intrahepatic cholangiocarcinoma (ICC) is an aggressive primary liver tumor with a general poor prognosis. Most patients present with unresectable disease at the time of diagnosis, and many patients who undergo resection with curative-intent will develop tumor recurrence [8]. In addition, reported 5-year OS after curativeintent hepatic resection is poor, ranging from 25 to $30 \%$ [9]. While ICC has been historically considered a rare tumor, its incidence has been markedly increasing in the past 2 decades [10,11]. Many risk factors for ICC development have been identified, among which obesity has been increasingly recognized as a factor associated with development of ICC [12-17]. Despite increasing interest in understanding the association of elevated BMI and ICC, to date, no study has investigated whether increased BMI impacts prognosis of patients undergoing resection of ICC. To this end, using an international multi-institutional database, the current study sought to assess the impact of BMI on tumor recurrence among patients undergoing curative-intent resection of ICC. Determining whether increased BMI influences oncologic outcomes of patients diagnosed with ICC may have clinical and societal implications, as overweight and obesity constitute both prevalent and modifiable risk factors for cancer.

\section{Methods}

\section{Data sources and study population}

A multi-institutional database representing 15 major tertiary hepatobiliary centers in the United States, Europe, Australia and Asia was used to identify patients who underwent resection of ICC between 1993 and 2015. The 15 institutions included The Ohio State University, Columbus, OH; Stanford University, Stanford, CA; University of Virginia, Charlottesville, VA; Emory University, Atlanta, GA; Fundeni Clinical Institute of Digestive Disease, Bucharest, Romania; Johns Hopkins Hospital, Baltimore, MD; Curry Cabral Hospital, Lisbon, Portugal; Ospedale San Raffaele, Milan, Italy; Royal Prince Alfred Hospital, University of Sydney, Sydney, Australia; Eastern Hepatobiliary Surgery Hospital, Shanghai, China; Beaujon Hospital, Clichy, France; University of Ottawa, Ottawa,
Ontario, Canada; Erasmus University Medical Centre, Rotterdam, Netherlands; University of Verona, Verona, Italy; and Yokohama City University School of Medicine, Yokohama, Japan. All patients diagnosed with ICC had histological confirmation of the disease. The study was approved by the Institutional Review Board of each participating institution.

Patients were categorized as normal weight, overweight and obese according to the World Health Organization (WHO) definition (normal weight: BMI 18.5-24.9; overweight: BMI 25.0-29.9; obese: $\mathrm{BMI} \geq 30 \mathrm{~kg} / \mathrm{m}^{2}$ ). Patients with missing information on BMI, as well as individuals with data missing on any specific factor included in the multivariable model, were excluded from the study.

\section{Data collection and follow-up}

Data on standard demographic, perioperative, clinicopathological, and tumor-related characteristics were collected. The severity of postoperative complications was determined according to the Clavien-Dindo Classification [18]. Based on final pathology reports, tumor characteristics including presence of liver cirrhosis, tumor morphology, tumor size, tumor focality, tumor number, presence of vascular/perineural/biliary/adjacent organ invasion, lymph node metastasis, and histological grade were assessed. Data on tumor stage were collected according to the American Joint Committee on Cancer (AJCC) 8th edition staging system. Patients with gallbladder cancer infiltrating the liver bed were not included in the study. Following surgical resection, patients were regularly followed with serum CEA, CA19-9, and abdominal CT or MRI. Recurrence was defined as an image showing a suspicious lesion or the presence of a biopsy proven tumor. Recurrence was further classified as intrahepatic, extrahepatic, or both intra- and extrahepatic. Recurrence interval was calculated from the date of the first surgery to the date of recurrence. Recurrence-free survival (RFS) was calculated from the date of surgery.

\section{Statistical analysis}

Continuous variables were reported as medians and interquartile ranges (IQR) and categorical variables were reported as total counts and frequencies. To assess the association between patient characteristics and BMI group, chi-squared tests and Wilcoxon rank-sum tests were utilized for continuous and categorical variables, respectively. To assess the associations between various clinicopathological factors with RFS, a Cox proportional hazards model was utilized. Variables for this model were selected on the basis of clinical significance and a backwards stepwise method. All variables were checked within the model to ensure they did not violate the proportional hazards assumption and all continuous variables were checked to ensure their functional form was linear. All analyses were conducted using SAS 9.4. Statistical significance was set at $\alpha=0.05$. 


\section{Results}

Tumor presentation and operative characteristics

Among a total of 790 patients undergoing curative-intent resection of ICC in the analytic cohort, 399 (50.5\%) were included in the normal weight, 274 (34.7\%) in the overweight and 117 (14.8\%) in the obese BMI categories (Table 1). Median patient age and gender were similar among patients who were of normal weight, overweight and obese. Patients who were Caucasian were more likely to be obese $(66.7 \%, \mathrm{n}=78)$ and overweight $(47.1 \%, \mathrm{n}=129)$ compared with Asians (obese: $18.8 \%, \mathrm{n}=22$; overweight: $46 \%$, $\mathrm{n}=126$ ) and other races (obese: $14.5 \%, \mathrm{n}=17$; overweight: $6.9 \%$, $\mathrm{n}=19)(\mathrm{p}<0.001)$. While obese patients were more likely to have a higher ASA score (ASA 3-4, obese: $50.5 \%, \mathrm{n}=56$; overweight: $29.8 \%, \mathrm{n}=77$; normal weight: $17.5 \%, \mathrm{n}=67, \mathrm{p}<0.001)$, there were no differences in the presence of cirrhosis (10.9\%, vs. $12.8 \%$, vs. $12.9 \%)$, preoperative jaundice ( $8.6 \%$ vs. $9.5 \%$ vs. $12.0 \%$ ), or levels of CA 19-9 (75, IQR 24.6-280 vs. 50.9, IQR $17.9-232$ vs. 43, IQR 16.9-192.7) among obese, overweight and patients with normal weight (all p > 0.05). Overall, only slight differences in tumor presentation among patients in the obese, overweight and normal weight BMI categories were observed. Specifically, obese, overweight and normal weight patients were as likely to present with mass forming (MF) morphological type (92.2\%, $\mathrm{n}=94$, vs. $89.1 \%$, $\mathrm{n}=230$, vs. $84.4 \%, \mathrm{n}=325)$, periductal infiltrative $(\mathrm{PI})(2.9 \%, \mathrm{n}=3$, vs. $3.5 \%, \mathrm{n}=9$ vs. $6.5 \%, \mathrm{n}=25)$ and combined $\mathrm{MF}+$ PI types ( $2 \%$, $\mathrm{n}=2$ vs. $3.9 \%, \mathrm{n}=10$ vs. $7.3 \%, \mathrm{n}=28)(\mathrm{p}=0.06)$. In addition, pathological characteristics such as tumor size, tumor focality, satellite lesions, vascular invasion, and tumor grade, among others, were comparable among all BMI categories (all p > 0.05). The presence of biliary invasion, however, was less likely to be observed among normal weight patients $(72.6 \%, \mathrm{n}=156)$ compared with overweight $(83.5 \%, n=137)$ and obese patients $(89.6 \%, n=86)$ $(\mathrm{p}<0.001)$. Moreover, AJCC 8th edition T and N stages were comparable among obese, overweight and normal weight patients ( $\mathrm{p}>0.05)$. Of note, obese patients were less likely to undergo a wedge resection ( $5.1 \%, \mathrm{n}=6$ vs. $20.8 \%, \mathrm{n}=57$, vs. $21.7 \%, \mathrm{n}=86$ ) and more likely to undergo a minor hepatectomy (35\%, $\mathrm{n}=41 \mathrm{vs.} 24.8 \%$, $\mathrm{n}=68$, vs. $23 \%, \mathrm{n}=91$ ) compared with overweight and normal weight patients. In addition, obese patients were slightly more likely to undergo a major hepatectomy compared with overweight and normal weight patients ( $59.8 \%, \mathrm{n}=70$ vs. $54.4 \%, \mathrm{n}=149$, vs. $55.3 \%, \mathrm{n}=219)(\mathrm{p}<0.001)$. Receipt of neoadjuvant therapy did not differ between the different BMI categories (obese: $7 \%$ vs. overweight: $8.9 \%$, vs. normal weight: $6.6 \%, \mathrm{p}=0.55$ ).

\section{Perioperative outcomes}

Overall, differences in perioperative outcomes of patients in the obese, overweight and normal weight BMI categories were minor (Table 2). Operative times (obese: $238 \mathrm{~min}$, IQR 150-333; overweight: $180 \mathrm{~min}$, IQR 108-310, normal weight: 180, 108-336, $\mathrm{p}=0.06$ ) and blood loss (obese: $400 \mathrm{ml}$, IQR 200-850, overweight: $300 \mathrm{ml}$, IQR 200-700, normal weight: 350, IQR 200-700, p = 0.20) were comparable among the three groups. On the other hand, the incidence of lymphadenectomy was lowest among overweight (40.7\%, $\mathrm{n}=110)$, followed by obese $(46.2 \%, \mathrm{n}=54)$ and normal weight $(52.4 \%, \mathrm{n}=209)$ patients $(\mathrm{p}=0.01)$. Nevertheless, median number of lymph nodes harvested were comparable among the three groups ( $1-5$ lymph nodes: obese, $11.1 \%, \mathrm{n}=13 \mathrm{vs}$. overweight, $12.4 \%, n=34$, vs: $n=641$; $\geq 6$ lymph nodes: obese, $88.9 \%, n=104$ vs. overweight, $87.6 \%, \mathrm{n}=240$ vs. normal weight, $83.2 \%, \mathrm{n}=332$ ) $(\mathrm{p}=0.15)$. Moreover, the incidence of $\mathrm{R} 0$ resection was also comparable among the three BMI categories (obese: $88.9 \%$ vs. overweight: $91.6 \%$ vs. normal weight: $88 \%, p=0.32$ ).

Both the incidence of postoperative complications (34.2\% vs. $36.6 \%$ vs. $38.3 \%, p=0.70$ ) and grade of complications were similar among obese, overweight and normal weight patients. Similarly, the incidence of post-hepatectomy liver failure (PHLF) (obese: 0.9\%, $\mathrm{n}=1$ vs. overweight: $0 \%$, vs. normal weight: $0.5 \%, \mathrm{n}=2, \mathrm{p}=0.39$ ) and bile leak (obese: $0.9 \%, n=1$ vs. overweight: $5.8 \%, n=16$, vs. normal weight: $5 \%, \mathrm{n}=20, \mathrm{p}=0.09$ ) did not differ among patients in the three BMI categories. Interestingly, median LOS was shorter among obese patients (9, IQR 5-15) compared with overweight (13, IQR 8-18) and normal weight patients (14, IQR 9-19) $(\mathrm{p}<0.001)$. Post-operatively, there was no difference in receipt of adjuvant chemotherapy (obese: 28\% vs. overweight: $29.2 \%$ vs. normal weight: $24.7 \%$ ) or radiotherapy (obese: $5.8 \%$ vs. overweight: $9.2 \%$ vs. normal weight: $4.5 \%$ ) among patients in the three groups (both $\mathrm{p}>0.05)$.

\section{Factors associated with RFS}

Overall, no difference in RFS was observed among obese, overweight and normal weight BMI categories (Fig. 1). Specifically, 1-, 3and 5-year RFS was 77.9\%, 49.5\% and 33.7\% among obese patients versus $81.4 \%, 48.7 \%$ and $36.8 \%$ among overweight patients; and $84.3 \%, 57.4 \%$ and $43.7 \%$, respectively, among normal weight patients $(\mathrm{p}=0.058)$.

On multivariable analysis, after controlling for competing risk factors, when BMI was analyzed as a continuous variable rather than categorized into categorical groups, every 5 unit increase in BMI was associated with a $16 \%$ increase in the odds of tumor recurrence (OR 1.16, 95\% CI 1.02-1.32). In addition to BMI, patients who had metastatic lymph nodes had an increased odds of tumor recurrence (OR 1.34, 95\% CI 1.02-1.75). Of note, Asian race was also associated with a higher odds of recurrence following curativeintent resection of ICC (Table 3). To account for observed differences among patients of Asian race, a sub-analysis including only Asian patients was performed. Of note, when analyzing only Asian patients, individuals in the overweight and obese BMI categories demonstrated a worse RFS compared with patients in the normal weight BMI category ( $\mathrm{p}<0.001$ ) (Fig. 2).

\section{Patterns of recurrence}

In total, 457 (57.9\%) out of 790 patients developed tumor recurrence. Among obese patients, 60.7\% $(n=71)$ developed a recurrence versus $59.1 \%(n=162)$ among overweight and $56.1 \%$ $(\mathrm{n}=224)$ among normal weight patients. Patterns of recurrence following initial ICC resection did not differ among patients in the obese, overweight and normal weight BMI categories (Fig. 3). Specifically, intrahepatic-only recurrence was observed in $60.8 \%$ $(\mathrm{n}=278)$ of patients (obese: $59.2 \%, \mathrm{n}=42$ vs. overweight: $57.4 \%$, $\mathrm{n}=93$ vs. normal weight: $63.8 \%, \mathrm{n}=143)$, while $19 \%(\mathrm{n}=87)$ of patients (obese: $19.7 \%, \mathrm{n}=14$ vs. overweight: $21 \%, \mathrm{n}=34$ vs. normal weight: $17.4 \%, \mathrm{n}=39$ ) experienced an extrahepatic recurrence, and 92 (20.1\%) patients (obese: $21.1 \%, \mathrm{n}=15$ vs. overweight: $21.6 \%, n=35$ vs. normal weight: $18.8 \%, n=42$ ) had combined intraand extrahepatic recurrence (all $\mathrm{p}>0.05$ ).

\section{Discussion}

While previous research have identified several pathological variables associated with prognosis of ICC, including CA 19-9 levels, tumor number and size, lymph node status, margin status, and vascular invasion, to the best of our knowledge, no previous study has specifically investigated the role of increased BMI as a prognostic factor among patients with ICC [19-26]. Among patients 
Table 1

Patient characteristics and tumor presentation of normal weight, overweight and obese patients who underwent curative-intent resection of ICC.

\begin{tabular}{|c|c|c|c|c|}
\hline Variables & Normal & Overweight & Obese & $P$-value \\
\hline Patients, n (\%) & 399 (50.5\%) & $274(34.7 \%)$ & $117(14.8 \%)$ & - \\
\hline Gender, n (\%) & & & & 0.08 \\
\hline Male & $233(58.4 \%)$ & $157(57.5 \%)$ & $55(47 \%)$ & \\
\hline Female & $166(41.6 \%)$ & $116(42.5 \%)$ & $62(53 \%)$ & \\
\hline Race & & & & $<0.001$ \\
\hline Caucasian & $139(34.8 \%)$ & $129(47.1 \%)$ & $78(66.7 \%)$ & \\
\hline Asian & $243(60.9 \%)$ & $126(46 \%)$ & $22(18.8 \%)$ & \\
\hline Other & $17(4.3 \%)$ & $19(6.9 \%)$ & $17(14.5 \%)$ & \\
\hline Continent & & & & $<0.001$ \\
\hline North America & $78(19.5 \%)$ & $78(28.5 \%)$ & $63(53.8 \%)$ & \\
\hline Europe & $87(21.8 \%)$ & $63(23 \%)$ & $29(24.8 \%)$ & \\
\hline Asia & $234(58.6 \%)$ & $123(44.9 \%)$ & $21(17.9 \%)$ & \\
\hline Australia & $10(3.6 \%)$ & $4(3.4 \%)$ & $4(3.5 \%)$ & \\
\hline Age, years, median (IQR) & $58.9(49.2,67.8)$ & $60(51.8,69.0)$ & $61.5(51.7,68.0)$ & 0.38 \\
\hline ASA score, $\mathrm{n}(\%)$ & & & & $<0.001$ \\
\hline $1-2$ & $316(82.5 \%)$ & $181(70.2 \%)$ & $55(49.5 \%)$ & \\
\hline $3-4$ & $67(17.5 \%)$ & $77(29.8 \%)$ & $56(50.5 \%)$ & \\
\hline Missing & 16 & 16 & 6 & \\
\hline Cirrhosis & & & & 0.15 \\
\hline No & $330(87.1 \%)$ & $218(87.2 \%)$ & $98(89.1 \%)$ & \\
\hline Yes & $49(12.9 \%)$ & $32(12.8 \%)$ & $12(10.9 \%)$ & \\
\hline Missing & 20 & 24 & 7 & \\
\hline CA19-9 & $43(16.9-192.7)$ & $50.9(17.9-232)$ & $75(24.6-280)$ & 0.24 \\
\hline Preoperative jaundice, n (\%) & & & & 0.60 \\
\hline No & $351(88 \%)$ & 247 (90.5\%) & 107 (91.5\%) & \\
\hline Yes & $48(12.0 \%)$ & $26(9.5 \%)$ & $10(8.6 \%)$ & \\
\hline Morphological type, n (\%) & & & & 0.06 \\
\hline MF & 325 (84.4\%) & $230(89.1 \%)$ & $94(92.2 \%)$ & \\
\hline IG & $7(1.8 \%)$ & $9(3.5 \%)$ & $3(2.9 \%)$ & \\
\hline PI & $25(6.5 \%)$ & $9(3.5 \%)$ & $3(2.9 \%)$ & \\
\hline $\mathrm{MF}+\mathrm{PI}$ & $28(7.3 \%)$ & $10(3.9 \%)$ & $2(2 \%)$ & \\
\hline Missing & 14 & 16 & 15 & \\
\hline Tumor size, n (\%) & & & & 0.88 \\
\hline$\leq 5 \mathrm{~cm}$ & $167(41.9 \%)$ & $119(43.4 \%)$ & $48(41 \%)$ & \\
\hline$>5 \mathrm{~cm}$ & $232(58.1 \%)$ & $155(56.6 \%)$ & $69(59 \%)$ & \\
\hline Lesion, n (\%) & & & & 0.50 \\
\hline Unifocal & $342(85.7 \%)$ & $231(84.3 \%)$ & $104(88.9 \%)$ & \\
\hline Multifocal & $57(14.3 \%)$ & $43(15.7 \%)$ & $13(11.1 \%)$ & \\
\hline Satellite lesions, n (\%) & & & & 0.41 \\
\hline No & $326(81.7 \%)$ & $212(77.7 \%)$ & $92(78.6 \%)$ & \\
\hline Yes & $73(18.3 \%)$ & $61(22.3 \%)$ & $25(21.4 \%)$ & \\
\hline Missing & 1 & & & \\
\hline Major vascular invasion, $\mathrm{n}(\%)$ & & & & 0.65 \\
\hline Not present & $353(88.5 \%)$ & $248(90.5 \%)$ & 105 (90.5\%) & \\
\hline Present & $46(11.5 \%)$ & $26(9.5 \%)$ & $11(9.5 \%)$ & \\
\hline Missing & 1 & & & \\
\hline Grade, n (\%) & & & & 0.37 \\
\hline Well - Moderate & $332(84.5 \%)$ & $217(83.8 \%)$ & $90(78.9 \%)$ & \\
\hline Poor - Undifferentiated & $61(15.5 \%)$ & $42(16.2 \%)$ & $24(21.1 \%)$ & \\
\hline Missing & 6 & 15 & 3 & \\
\hline Perineural invasion, n (\%) & & & & 0.49 \\
\hline Not present & $306(82.9 \%)$ & $217(86.5 \%)$ & $85(85 \%)$ & \\
\hline Present & $63(17.1 \%)$ & $34(13.5 \%)$ & $15(15 \%)$ & \\
\hline Missing & 30 & 23 & 17 & \\
\hline Biliary invasion, n (\%) & & & & $<0.001$ \\
\hline No & $59(27.4 \%)$ & $27(16.5 \%)$ & $10(10.4 \%)$ & \\
\hline Yes & $156(72.6 \%)$ & $137(83.5 \%)$ & $86(89.6 \%)$ & \\
\hline Missing & 184 & 110 & 21 & \\
\hline Liver capsule involvement, $\mathrm{n}(\%)$ & & & & 0.35 \\
\hline No & $354(88.7 \%)$ & $243(88.7 \%)$ & 109 (93.2\%) & \\
\hline Yes & $45(11.3 \%)$ & $31(11.3 \%)$ & $8(6.8 \%)$ & \\
\hline AJCC 8th edition $\mathrm{N}$ stages, $\mathrm{n}(\%)$ & & & & 0.14 \\
\hline $\mathrm{Nx}$ & $602(76.2 \%)$ & $289(72.4 \%)$ & $218(79.6 \%)$ & \\
\hline NO & $60(7.6 \%)$ & $33(8.3 \%)$ & $20(7.3 \%)$ & \\
\hline $\mathrm{N} 1$ & $128(16.2 \%)$ & $77(19.3 \%)$ & $36(13.1 \%)$ & \\
\hline AJCC 8th edition T stages, $\mathrm{n}(\%)$ & & & & 0.81 \\
\hline T1a & $99(24.8 \%)$ & $75(27.4 \%)$ & $28(23.9 \%)$ & \\
\hline $\mathrm{T} 1 \mathrm{~b}$ & $105(26.3 \%)$ & $73(26.6 \%)$ & $33(28.2 \%)$ & \\
\hline $\mathrm{T} 2$ & $139(34.8 \%)$ & $90(32.8 \%)$ & $45(38.5 \%)$ & \\
\hline T3 & $37(9.3 \%)$ & $28(10.2 \%)$ & $8(6.8 \%)$ & \\
\hline $\mathrm{T} 4$ & $19(4.8 \%)$ & $8(2.9 \%)$ & $3(2.6 \%)$ & \\
\hline Type of surgery, n (\%) & & & & $<0.001$ \\
\hline Wedge resection & $86(21.7 \%)$ & $57(20.8 \%)$ & $6(5.1 \%)$ & \\
\hline Minor hepatectomy & $91(23 \%)$ & $68(24.8 \%)$ & $41(35 \%)$ & \\
\hline Major hepatectomy & $219(55.3 \%)$ & $149(54.4 \%)$ & $70(59.8 \%)$ & \\
\hline
\end{tabular}


Table 1 (continued)

\begin{tabular}{|c|c|c|c|c|}
\hline Variables & Normal & Overweight & Obese & $P$-value \\
\hline Missing & 3 & & & \\
\hline Neoadjuvant chemotherapy, n (\%) & & & & 0.55 \\
\hline No & $352(93.4 \%)$ & $235(91.1 \%)$ & $106(93 \%)$ & \\
\hline Yes & $25(6.6 \%)$ & $23(8.9 \%)$ & $8(7 \%)$ & \\
\hline Missing & 22 & 16 & 3 & \\
\hline
\end{tabular}

Table 2

Bivariate analysis of outcomes of normal weight, overweight and obese patients.

\begin{tabular}{|c|c|c|c|c|}
\hline Variables & Normal & Overweight & Obese & $P$-value \\
\hline Operative time median (IQR) & $180(108-336)$ & $180(108-310)$ & $238(150-333)$ & 0.06 \\
\hline Blood loss median (IQR) & $350(200,700)$ & $300(200,700)$ & $400(200,850)$ & 0.20 \\
\hline Blood transfusion & & & & 0.91 \\
\hline Yes & $290(76.5 \%)$ & $193(77.5 \%)$ & $80(75.5 \%)$ & \\
\hline No & $89(23.5 \%)$ & $56(22.5 \%)$ & $26(24.5 \%)$ & \\
\hline Missing & 20 & 25 & 11 & \\
\hline Lymphadenectomy & & & & 0.01 \\
\hline Yes & 209 (52.4\%) & $111(40.7 \%)$ & $54(46.2 \%)$ & \\
\hline No & 190 (47.6\%) & $162(59.3 \%)$ & $63(53.8 \%)$ & \\
\hline Missing & 1 & 0 & 0 & \\
\hline \multicolumn{5}{|l|}{ LND harvest rate } \\
\hline $1-5$ & $67(16.8 \%)$ & $34(12.4 \%)$ & $13(11.1 \%)$ & 0.15 \\
\hline$\geq 6$ & $332(83.2 \%)$ & $240(87.6 \%)$ & $104(88.9 \%)$ & \\
\hline Lymph node ratio & & & & 0.21 \\
\hline 0 & $88(53.3 \%)$ & $62(63.3 \%)$ & $34(69.4 \%)$ & \\
\hline$<0.25$ & $19(11.5 \%)$ & $11(11.2 \%)$ & $5(10.2 \%)$ & \\
\hline $0.26-0.50$ & $23(13.9 \%)$ & $6(6.1 \%)$ & $2(4.1 \%)$ & \\
\hline$>0.50$ & $35(21.2 \%)$ & $19(19.4 \%)$ & $8(16.3 \%)$ & \\
\hline Missing & 234 & 176 & 68 & \\
\hline $\mathrm{R} 1$ resection & $48(12 \%)$ & $23(8.4 \%)$ & $13(11.1 \%)$ & 0.32 \\
\hline R0 resection & $351(88 \%)$ & 251 (91.6\%) & $104(88.9 \%)$ & \\
\hline Complication & & & & 0.70 \\
\hline Yes & $153(38.3 \%)$ & $100(36.6 \%)$ & $40(34.2 \%)$ & \\
\hline No & $246(61.7 \%)$ & $173(63.4 \%)$ & 77 (65.8\%) & \\
\hline Missing & 1 & 0 & 0 & \\
\hline Grade of complication & & & & 0.29 \\
\hline Clavien-Dindo I & $56(14 \%)$ & $40(14.6 \%)$ & $11(9.4 \%)$ & \\
\hline Clavien-Dindo II & $40(10 \%)$ & $31(11.3 \%)$ & $17(14.5 \%)$ & \\
\hline Clavien-Dindo III & $283(70.9 \%)$ & $195(71.2 \%)$ & $79(67.5 \%)$ & \\
\hline Clavien Dindo-IV & $12(3 \%)$ & $6(2.2 \%)$ & $7(6 \%)$ & \\
\hline Clavien-Dindo V & $8(2 \%)$ & $2(0.7 \%)$ & $3(2.6 \%)$ & \\
\hline Bile leak & $20(5 \%)$ & $16(5.8 \%)$ & $1(0.9 \%)$ & 0.09 \\
\hline PHLF & $2(0.5 \%)$ & $0(0.0 \%)$ & $1(0.9 \%)$ & 0.39 \\
\hline LOS, median (IQR) & $14(9-19)$ & $13(8-18)$ & $9(5-15)$ & $<0.001$ \\
\hline 30- day readmission & $17(4.6 \%)$ & $15(6.1 \%)$ & $7(6.7 \%)$ & 0.61 \\
\hline 90-mortality & $6(1.6 \%)$ & $2(0.8 \%)$ & $4(3.8 \%)$ & 0.12 \\
\hline Adjuvant chemotherapy & $95(24.7 \%)$ & $79(29.2 \%)$ & $30(28 \%)$ & 0.42 \\
\hline Adjuvant radiotherapy & $17(4.5 \%)$ & $24(9.2 \%)$ & $6(5.8 \%)$ & 0.06 \\
\hline
\end{tabular}

with ICC, the ability to predict prognosis accurately after surgical resection remains poor, with most prognostic/predictive tools performing only moderately at best $[27,28]$. Accurate estimation of recurrence risk and long-term survival is important, however, to guide perioperative management of patients undergoing surgical resection with curative-intent, as well as for adequate informed consent and shared decision-making. As such, the current study is important because it reports one of the largest multi-institutional experiences on the surgical management of ICC. Of note, we found that increased BMI among patients undergoing curativeintent resection of ICC is associated with increased risk of recurrence. The understanding of risk factors associated with poor prognosis is important to guide future interventions directed at improving long-term outcomes of patients with ICC.

Calle et al. reported on a population of more than 900,000 U.S. adults and noted that obesity was associated with increased death rates for all cancers combined, as well as for cancers at multiple specific sites [29]. Indeed, a growing body of literature has demonstrated that obese patients with cancer often have worse oncologic outcomes independent of disease presentation and stage. For example, among patients with early stage breast cancer treated with curative-intent, obesity has been associated with locoregional recurrence and distant metastases, as well as breast-cancer specific mortality [30,31]. In addition, a separate study that examined patients with stage II-III colon cancer reported that BMI $>35 \mathrm{~kg} / \mathrm{m}^{2}$ was associated with a $38 \%$ increased risk of recurrence and a $36 \%$ increased risk of disease-specific mortality [32]. Similarly, in a multicenter study of patients undergoing radical cystectomy, Chromecki et al. identified obesity as an independent predictor of disease recurrence (HR 1.67, 95\% CI 1.46-1.91) and cancer-specific mortality (HR 1.43, 95\% CI 1.24-1.66) [33]. Similar associations between increased BMI and poor oncologic outcomes have been observed in other gastrointestinal solid tumors, genitourinary and hematological malignancies [29,34-37]. To date, among patients with primary liver cancers, previous research has almost completely focused on patients with hepatocellular carcinoma 


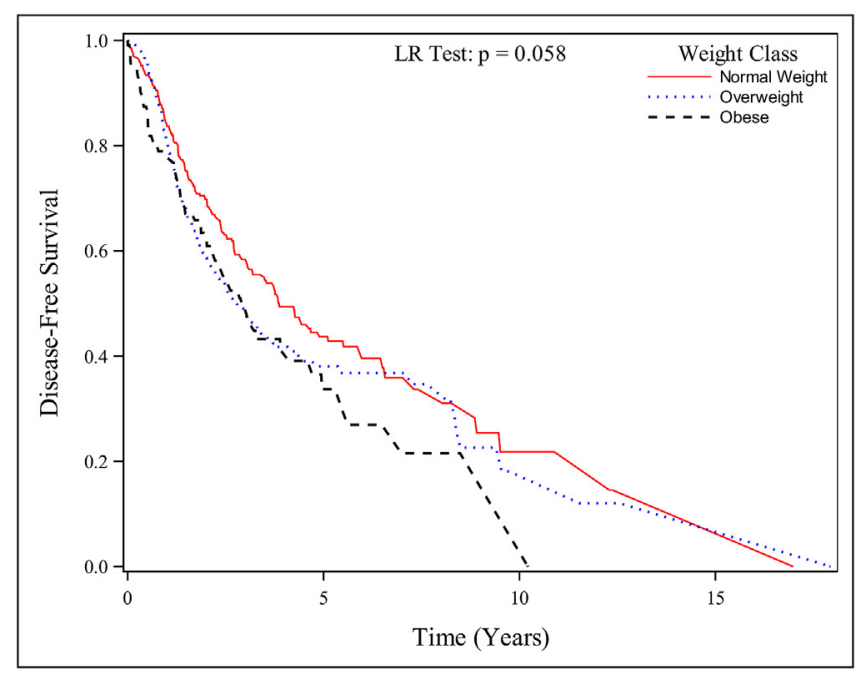

Fig. 1. Recurrence-free survival of obese, overweight and normal weight patients.

Table 3

Multivariable analysis of factors associated with recurrence-free survival.

\begin{tabular}{llll}
\hline & OR & CI & p-value \\
\hline BMI (+5 units) & 1.16 & $1.02-1.32$ & $\mathbf{0 . 0 2 1}$ \\
Age (+5 years) & 1.09 & $1.03-1.15$ & $\mathbf{0 . 0 0 1}$ \\
$\begin{array}{l}\text { Metastatic lymph nodes } \\
\quad \text { Yes }\end{array}$ & $\begin{array}{l}1.34 \\
\text { ref }\end{array}$ & $1.02-1.75$ & $\mathbf{0 . 0 3 7}$ \\
No & & - & \\
Race & 1.66 & $1.23-2.42$ & $<\mathbf{0 . 0 0 1}$ \\
Asian & ref & - & \\
$\quad$ Others & & & \\
\hline
\end{tabular}

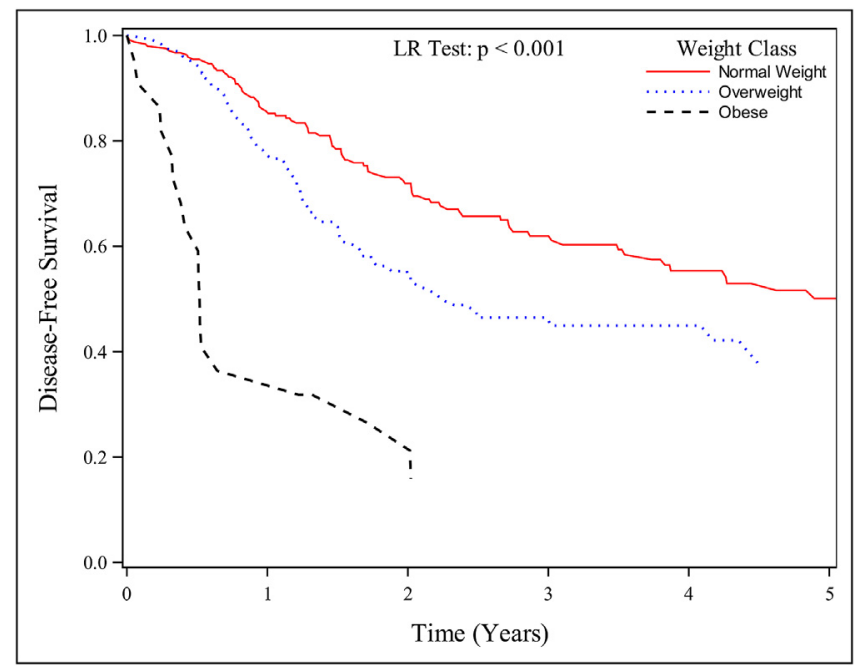

Fig. 2. Recurrence-free survival of obese, overweight and normal weight patients in a subset of patients of Asian race.

(HCC) [38-41]. For example, Shinkawa et al. reported that obesity was an independent risk for worse RFS (HR 2.8; 95\% CI 1.3-6.1) among HCV-related HCC patients with preoperative sustained virological response [40]. Moreover, Mathur et al. noted that obese and overweight individuals had doubled the incidence of recurrence compared with non-obese group after transplantation for HCC (15\% vs. $7 \%, \mathrm{p}<0.05)$ [39].

After surgical resection of ICC, the incidence of recurrence can

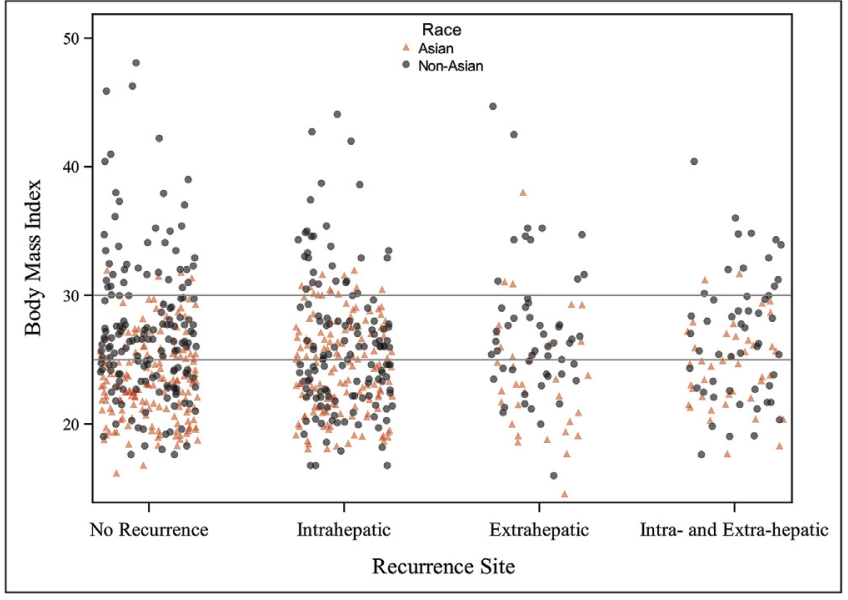

Fig. 3. Patterns of tumor recurrence among obese, overweight and normal weight patients.

be high ranging from $46 \%$ to $65 \%$ [ 42 ]. Although several pathologic characteristics associated with less favorable ICC prognosis have been identified, currently available nomograms and staging systems have demonstrated only a limited ability to predict RFS and OS. In fact, our own group demonstrated that even among patients with "favorable" tumor pathology - i.e., unifocal disease, MF-ICC morphology, no lymph node metastasis, tumor size $<5 \mathrm{~cm}$, and well-to-moderately differentiated tumor grade - most patients have considerably shorter recurrence intervals than would be predicted [27]. Several authors have hypothesized that the suboptimal predictive ability of current prognostic tools developed relates to the need to include other - yet-to-be identified - prognostic variables [26,43,44]. Interestingly, while predictive tools have considered clinical characteristics such as patient age and sex, no previous studies have included BMI or race as possible prognostic factors [26,27,43-45]. As such, the findings of the current study were particularly relevant, as we demonstrated that increasing BMI was independently associated with incremental increases in the risk of recurrence after curative-intent resection among patients with ICC. Specifically, on multivariable analysis of factors associated with recurrence, every 5 unit increase in patient BMI was associated $16 \%$ increase in the risk of recurrence. Of note, Asian race was also an independent prognostic factor for tumor recurrence, and among this subset of patients, patients in the overweight and obesity BMI categories had significantly worse RFS (Fig. 2).

While the current study was not designed to elucidate the mechanistic underpinnings of increased BMI relative to recurrence of ICC, several findings were notable. Despite the fact that initial tumor presentation, perioperative outcomes and patterns of recurrence did not differ among the different BMI categories, increasing BMI was still associated with increased odds of tumor recurrence. These results reinforce the hypothesis that factors beyond classical tumor characteristics impact prognosis of patients with ICC. Recently, advances in epigenomics studies have demonstrated important associations among different gene expression patterns and different states of diseases and/or medical conditions [46]. DNA methylation, a well-known and critical regulation level of the epigenetic machinery, is easily modulated by environmental factors [47-49]. Several studies have demonstrated that altered DNA methylation patterns in some metabolically important genes are a consequence of high BMI [50-53]. In fact, Gu et al. recently described BMI-associated epigenetic alterations in cholangiocarcinomas [54]. Additionally, genomic alterations were also described among etiologically distinct subtypes of 
cholangiocarcinoma [55]. Specifically, Jusakul et al. reported four distinct subtypes of ICC with different clinical and genomic characteristics that have distinct prognoses. Moreover, dysfunctional adipose tissue in obese patients can release adipokines that elevate levels of pro-inflammatory factors, producing a state of chronic inflammation [56-59]. One such adipokine is CXCL5, a chemokine involved in angiogenesis, which when overexpressed is associated with advanced tumor stages, local invasion and increased metastatic potential. For example, among patients with pancreatic cancer, overexpression of CXCL5 has been associated with poor oncologic outcomes [60]. Importantly, a recent study demonstrated that the expression of CXCL5 was an independent predictor of OS and time to recurrence in patients with ICC [61]. As obesity promotes a state of chronic inflammation, future studies will need to investigate the associations of distinct gene expression patterns, as well as genetic mutations, among patients with increased BMI.

The results of the current study should be interpreted in light of several limitations. Similar to other retrospective and multiinstitutional studies, the current analysis may have been subject to selection bias and heterogeneity in perioperative ICC treatments. In addition, the definition of obesity, overweight and normal weight was based on the calculation of patient BMI, which cannot differentiate between adipose tissue and lean mass. Therefore, BMI may underestimate the prevalence of visceral obesity in the population, which might result in potential biases of the association between obesity and outcomes towards the null effect [57]. Nevertheless, due to non-feasibility of quantification of visceral adipose tissue through imaging for population-based studies, BMI has been widely adopted and accepted for the definition of weight categories for research purposes [54]. Moreover, the database did not provide information regarding the presence of non-alcoholic steatohepatitis (NASH) or non-alcoholic fatty liver disease (NAFLD). While it is recognized that the incidence of NAFLD and $\mathrm{NASH}$ is more prevalent among overweight and obese patients, previous studies using a similar cohort of patients have found that recurrence-free and overall survival after hepatic resection of ICC are comparable in NASH versus non-NASH patients [62]. The database also lacked data on metabolic syndrome and the comorbidities that define the syndrome, as well as other comorbidities such as chronic kidney disease, chronic obstructive pulmonary disease, among others.

In conclusion, when BMI was analyzed as continuous variable, incremental increases in BMI were associated with increased risk of recurrence following curative-intent resection of ICC. In addition, among Asian patients the impact of overweight and obesity on RFS was particularly pronounced. Given the increasing incidence of ICC, parallel to the continuous increase in the incidence of overweight, obese and severely obese adults worldwide, a better characterization of the prognostic role of patients' BMI in ICC is needed to guide appropriate interventions. Future research aimed at understanding factors that go beyond classic pathologic characteristics of ICC and elucidate mechanisms associated with worse outcomes is warranted.

\section{References}

[1] Flegal KM, Kruszon-Moran D, Carroll MD, Fryar CD, Ogden CL. Trends in obesity among adults in the United States, 2005 to 2014. J Am Med Assoc 2016;315(21):2284-91.

[2] Finkelstein EA, Khavjou OA, Thompson H, Trogdon JG, Pan L, Sherry B, et al. Obesity and severe obesity forecasts through 2030. Am J Prev Med 2012;42(6):563-70.

[3] Wang YC, McPherson K, Marsh T, Gortmaker SL, Brown M. Health and economic burden of the projected obesity trends in the USA and the UK. Lancet 2011;378(9793):815-25.

[4] Ballard-Barbash RBD, Potischmann N, Dowling E. Obesity and cancer epidemiology. Springer; 2010.
[5] Ma Y, Yang Y, Wang F, Zhang P, Shi C, Zou Y, et al. Obesity and risk of colorectal cancer: a systematic review of prospective studies. PLoS One 2013;8(1). e53916.

[6] Berger NA. Obesity and cancer pathogenesis. Ann N Y Acad Sci 2014;1311: 57-76.

[7] Lauby-Secretan B, Scoccianti C, Loomis D, Grosse Y, Bianchini F, Straif K, et al Body fatness and cancer-viewpoint of the IARC working group. N Engl J Med 2016;375(8):794-8.

[8] Razumilava N, Gores GJ. Cholangiocarcinoma. Lancet 2014;383(9935): 2168-79.

[9] Hyder O, Hatzaras I, Sotiropoulos GC, Paul A, Alexandrescu S, Marques H, et al Recurrence after operative management of intrahepatic cholangiocarcinoma. Surgery 2013;153(6):811-8.

[10] Patel T. Increasing incidence and mortality of primary intrahepatic cholangiocarcinoma in the United States. Hepatology 2001;33(6):1353-7.

[11] Cardinale V, Semeraro R, Torrice A, Gatto M, Napoli C, Bragazzi MC, et al. Intrahepatic and extra-hepatic cholangiocarcinoma: new insight into epidemiology and risk factors. World J Gastrointest Oncol 2010;2(11):407-16.

[12] Tyson GL, El-Serag HB. Risk factors for cholangiocarcinoma. Hepatology 2011;54(1):173-84.

[13] Palmer WC, Patel T. Are common factors involved in the pathogenesis of primary liver cancers? A meta-analysis of risk factors for intrahepatic cholangiocarcinoma. J Hepatol 2012;57(1):69-76.

[14] Grainge MJ, West J, Solaymani-Dodaran M, Aithal GP, Card TR. The antecedents of biliary cancer: a primary care case-control study in the United Kingdom. Br J Canc 2009;100(1):178-80.

[15] Li JS, Han TJ, Jing N, Li L, Zhang XH, Ma FZ, et al. Obesity and the risk of cholangiocarcinoma: a meta-analysis. Tumour Biol 2014;35(7):6831-8.

[16] Petrick JL, Thistle JE, Zeleniuch-Jacquotte A, Zhang X, Wactawski-Wende J Van Dyke AL, et al. Body mass index, diabetes and intrahepatic cholangiocarcinoma risk: the liver cancer pooling project and meta-analysis. Am J Gastroenterol 2018;113(10):1494-505.

[17] Petrick JL, Yang B, Altekruse SF, Van Dyke AL, Koshiol J, Graubard BI, et al. Risk factors for intrahepatic and extrahepatic cholangiocarcinoma in the United States: a population-based study in SEER-Medicare. PLoS One 2017;12(10). e0186643.

[18] Dindo D, Demartines N, Clavien PA. Classification of surgical complications: a new proposal with evaluation in a cohort of 6336 patients and results of a survey. Ann Surg 2004;240(2):205-13.

[19] Lafaro K, Grandhi MS, Herman JM, Pawlik TM. The importance of surgical margins in primary malignancies of the liver. J Surg Oncol 2016;113(3): 296-303.

[20] Mavros MN, Economopoulos KP, Alexiou VG, Pawlik TM. Treatment and prognosis for patients with intrahepatic cholangiocarcinoma: systematic review and meta-analysis. JAMA Surg 2014;149(6):565-74.

[21] Bagante F, Weiss M, Alexandrescu S, Marques HP, Aldrighetti L, Maithel SK, et al. Long-term outcomes of patients with intraductal growth sub-type of intrahepatic cholangiocarcinoma. HPB (Oxford) 2018;20(12):1189-97.

[22] Spolverato G, Yakoob MY, Kim Y, Alexandrescu S, Marques HP, Lamelas J, et al Impact of complications on long-term survival after resection of intrahepatic cholangiocarcinoma. Cancer 2015;121(16):2730-9.

[23] Spolverato G, Yakoob MY, Kim Y, Alexandrescu S, Marques HP, Lamelas J, et al The impact of surgical margin status on long-term outcome after resection for intrahepatic cholangiocarcinoma. Ann Surg Oncol 2015;22(12):4020-8.

[24] Hu LS, Weiss M, Popescu I, Marques HP, Aldrighetti L, Maithel SK, et al. Impact of microvascular invasion on clinical outcomes after curative-intent resection for intrahepatic cholangiocarcinoma. J Surg Oncol 2019;119(1):21-9.

[25] Buettner S, Galjart B, van Vugt JLA, Bagante F, Alexandrescu S, Marques HP, et al. Performance of prognostic scores and staging systems in predicting long-term survival outcomes after surgery for intrahepatic cholangiocarcinoma. J Surg Oncol 2017;116(8):1085-95.

[26] Wang Y, Li J, Xia Y, Gong R, Wang K, Yan Z, et al. Prognostic nomogram for intrahepatic cholangiocarcinoma after partial hepatectomy. J Clin Oncol 2013;31(9):1188-95.

[27] Bagante F, Merath K, Squires MH, Weiss M, Alexandrescu S, Marques HP, et al. The limitations of standard clinicopathologic features to accurately riskstratify prognosis after resection of intrahepatic cholangiocarcinoma. J Gastrointest Surg 2018;22(3):477-85.

[28] de Jong MC, Nathan H, Sotiropoulos GC, Paul A, Alexandrescu S, Marques H, et al. Intrahepatic cholangiocarcinoma: an international multi-institutional analysis of prognostic factors and lymph node assessment. J Clin Oncol 2011;29(23):3140-5.

[29] Calle EE, Rodriguez C, Walker-Thurmond K, Thun MJ. Overweight, obesity, and mortality from cancer in a prospectively studied cohort of U.S. adults. N Engl J Med 2003;348(17):1625-38.

[30] Bastarrachea J, Hortobagyi GN, Smith TL, Kau SW, Buzdar AU. Obesity as an adverse prognostic factor for patients receiving adjuvant chemotherapy for breast cancer. Ann Intern Med 1994;120(1):18-25.

[31] Ewertz M, Jensen MB, Gunnarsdóttir K, Højris I, Jakobsen EH, Nielsen D, et al Effect of obesity on prognosis after early-stage breast cancer. J Clin Oncol 2011;29(1):25-31.

[32] Dignam JJ, Polite BN, Yothers G, Raich P, Colangelo L, O'Connell MJ, et al. Body mass index and outcomes in patients who receive adjuvant chemotherapy for colon cancer. J Natl Cancer Inst 2006;98(22):1647-54.

[33] Gild P, Ehdaie B, Kluth LA. Effect of obesity on bladder cancer and renal cel 
carcinoma incidence and survival. Curr Opin Urol 2017;27(5):409-14.

[34] Protani MM, Nagle CM, Webb PM. Obesity and ovarian cancer survival: systematic review and meta-analysis. Cancer Prev Res (Phila) 2012;5(7): 901-10.

[35] Meyerhardt JA, Niedzwiecki D, Hollis D, Saltz LB, Mayer RJ, Nelson H, et al. Impact of body mass index and weight change after treatment on cancer recurrence and survival in patients with stage III colon cancer: findings from Cancer and Leukemia Group B 89803. J Clin Oncol 2008;26(25):4109-15.

[36] Sinicrope FA, Foster NR, Yothers G, Benson A, Seitz JF, Labianca R, et al. Body mass index at diagnosis and survival among colon cancer patients enrolled in clinical trials of adjuvant chemotherapy. Cancer 2013;119(8):1528-36.

[37] Simkens LH, Koopman M, Mol L, Veldhuis GJ, Ten Bokkel Huinink D, Muller EW, et al. Influence of body mass index on outcome in advanced colorectal cancer patients receiving chemotherapy with or without targeted therapy. Eur J Cancer 2011;47(17):2560-7.

[38] Wu SE, Charles HW, Park JS, Goldenberg AS, Deipolyi AR. Obesity conveys poor outcome in patients with hepatocellular carcinoma treated by transarterial chemoembolization. Diagn Interv Imaging 2017;98(1):37-42.

[39] Mathur A, Franco ES, Leone JP, Osman-Mohamed H, Rojas H, Kemmer N, et al. Obesity portends increased morbidity and earlier recurrence following liver transplantation for hepatocellular carcinoma. HPB (Oxford) 2013;15(7): 504-10.

[40] Shinkawa H, Tanaka S, Takemura S, Ito T, Aota T, Koda M, et al. Obesity and recurrence-free survival in patients with hepatocellular carcinoma after achieving sustained virological response to interferon therapy for chronic hepatitis C. Ann Gastroenterol Surg 2018;2(4):319-26.

[41] Kobayashi A, Kaido T, Hamaguchi Y, Okumura S, Shirai H, Yao S, et al. Impact of sarcopenic obesity on outcomes in patients undergoing hepatectomy for hepatocellular carcinoma. Ann Surg 2017.

[42] Miyazaki M, Shimizu H, Yoshitomi H, Kato A, Furukawa K, Takayashiki T, et al. Clinical implication of surgical resection for recurrent biliary tract cancer: does it work or not? Ann Gastroenterol Surg 2017;1(3):164-70.

[43] Hyder O, Marques H, Pulitano C, Marsh JW, Alexandrescu S, Bauer TW, et al. A nomogram to predict long-term survival after resection for intrahepatic cholangiocarcinoma: an Eastern and Western experience. JAMA Surg $2014 ; 149(5): 432-8$.

[44] Sakamoto Y, Kokudo N, Matsuyama Y, Sakamoto M, Izumi N, Kadoya M, et al. Proposal of a new staging system for intrahepatic cholangiocarcinoma: analysis of surgical patients from a nationwide survey of the Liver Cancer Study Group of Japan. Cancer 2016;122(1):61-70.

[45] Raoof M, Dumitra S, Ituarte PHG, Melstrom L, Warner SG, Fong Y, et al Development and validation of a prognostic score for intrahepatic cholangiocarcinoma. JAMA Surg 2017;152(5). e170117.

[46] Rakyan VK, Down TA, Balding DJ, Beck S. Epigenome-wide association studies for common human diseases. Nat Rev Genet 2011;12(8):529-41.
[47] Portela A, Esteller M. Epigenetic modifications and human disease. Nat Biotechnol 2010:28(10):1057-68.

[48] Lienert F, Wirbelauer C, Som I, Dean A, Mohn F, Schübeler D. Identification of genetic elements that autonomously determine DNA methylation states. Nat Genet 2011;43(11):1091-7.

[49] Feil R, Fraga MF. Epigenetics and the environment: emerging patterns and implications. Nat Rev Genet 2012;13(2):97-109.

[50] Wahl S, Drong A, Lehne B, Loh M, Scott WR, Kunze S, et al. Epigenome-wide association study of body mass index, and the adverse outcomes of adiposity. Nature 2017;541(7635):81-6.

[51] Geach T. Obesity: methylation a consequence not a cause. Nat Rev Endocrinol 2017;13(3):127.

[52] Crujeiras AB, Diaz-Lagares A, Sandoval J, Milagro FI, Navas-Carretero S, Carreira MC, et al. DNA methylation map in circulating leukocytes mirrors subcutaneous adipose tissue methylation pattern: a genome-wide analysis from non-obese and obese patients. Sci Rep 2017:7:41903.

[53] Dick KJ, Nelson CP, Tsaprouni L, Sandling JK, Aïssi D, Wahl S, et al. DNA methylation and body-mass index: a genome-wide analysis. Lancet 2014;383(9933):1990-8.

[54] Gu Y, Zhang CW, Wang L, Zhao Y, Wang H, Ye Q, et al. Association analysis between body mass index and genomic DNA methylation across 15 major cancer types. J Cancer 2018;9(14):2532-42.

[55] Jusakul A, Cutcutache I, Yong CH, Lim JQ Huang MN, Padmanabhan N, et al. Whole-Genome and epigenomic landscapes of etiologically distinct subtypes of cholangiocarcinoma. Cancer Discov 2017;7(10):1116-35.

[56] Divella R, De Luca R, Abbate I, Naglieri E, Daniele A. Obesity and cancer: the role of adipose tissue and adipo-cytokines-induced chronic inflammation. J Cancer 2016;7(15):2346-59.

[57] Allott EH, Hursting SD. Obesity and cancer: mechanistic insights from transdisciplinary studies. Endocr Relat Cancer 2015:22(6):R365-86.

[58] Sun B, Karin M. Obesity, inflammation, and liver cancer. J Hepatol 2012;56(3): 704-13.

[59] Avgerinos KI, Spyrou N, Mantzoros CS, Dalamaga M. Obesity and cancer risk: emerging biological mechanisms and perspectives. Metabolism 2018;92: $121-35$.

[60] Li A, King J, Moro A, Sugi MD, Dawson DW, Kaplan J, et al. Overexpression of CXCL5 is associated with poor survival in patients with pancreatic cancer. Am J Pathol 2011;178(3):1340-9.

[61] Zhou SL, Dai Z, Zhou ZJ, Chen Q, Wang Z, Xiao YS, et al. CXCL5 contributes to tumor metastasis and recurrence of intrahepatic cholangiocarcinoma by recruiting infiltrative intratumoral neutrophils. Carcinogenesis 2014;35(3): 597-605.

[62] Reddy SK, Hyder O, Marsh JW, Sotiropoulos GC, Paul A, Alexandrescu S, et al. Prevalence of nonalcoholic steatohepatitis among patients with resectable intrahepatic cholangiocarcinoma. J Gastrointest Surg 2013;17(4):748-55. 